\title{
Doing the document: Gender studies at the corporatized university in Europe. Part 2: Answering the sixty- four-thousand-dollar question
}

European Journal of Women's Studies 2014, Vol. 21 (2) 194-199 (C) The Author(s) 2014 Reprints and permissions: sagepub.co.uk/journalsPermissions.nav DOI: $10.1177 /|3505068| 351906$ | ejw.sagepub.com

\section{Rosemarie Buikema and Iris van der Tuin}

University of Utrecht, The Netherlands

11 September 2012. It is beautiful outside. Lingering summer. We are gathered at Castrum Peregrini at the Herengracht in Amsterdam, our inter(p)lace, to celebrate the hundredth birthday of Castrum Peregrini's grand old lady Gisèle van Waterschoot van der Gracht. Michael, inter(p)lace Castrum Peregrini's current director, is holding the microphone and recollects some memories from Gisèle's incredible life, which has been connected to all the grand histories of last century's Europe. Her paintings have been brought to the reception space for the occasion, a moving self-portrait among others. Look, there is our student Anaï; she is currently fulfilling her internship at Castrum anticipating further cooperation with this cultural heritage site. And there is our former Minister of Emancipation. She must be in her seventies by now, and was one of our panelists at the 7th European Feminist Research Conference, hosted by Utrecht University. She is waving to us while holding Gisèle's hand and talking loudly into her ear. Gisèle is dressed as if she just arrived from 1930s Paris's left bank. Although we are in the process of digesting two major rejections of our intended EU research project with Castrum Peregrini: this is still our presence.

This Open Forum piece is the second part of a longer argument concerning the vicissitudes of doing gender research at the corporate university in Europe, which we started in an essay published in European Journal of Women's Studies Vol. 20, No. 3. We have structured our argument around several vignettes that communicate the circumstances under which we have worked on our project 'INTER(P)LACES'. INTER(P)LACES currently exists as a consortium: we are in the process of applying for money for the consortium to materialize as a European $\mathrm{PhD}$ training and research network. This

\section{Corresponding author:}

Rosemarie Buikema, University of Utrecht, Netherlands Research School of Genderstudies (NOG),

Muntstraat 2A|, Utrecht, 3512 EV, The Netherlands.

Email: r.l.buikema@uu.nl 
process concerns the production of documents, and we write these pieces in EJWS in order to ask: what kinds of documents are we talking about, and how come we are so invested in their production? The analysis of our work may teach us something about where gender studies is at in the second decade of the 21 st century. The corporatization of academia went incredibly fast, and therefore we feel the need to pause and work through the current climate. Writing the vignettes was our first step, analysing them is done in the articles.

Let us start by refreshing your memory. 'INTER(P)LACES' is the acronym of a European consortium that aspires to train graduates in Transnational Memory Studies (TMS) and Cultural Heritage Management from a feminist perspective. As a consortium we have been applying for research and networking monies from the European Commission. The drafting of the project proposals is led by the Graduate Gender Programme of Utrecht University and Castrum Peregrini, an Amsterdam-based cultural centre. ${ }^{1}$ Starting from the founding assumption within TMS that memories are always mediated and thus subjected to processes of in- and exclusion, we stage the project as a means to educate future scholars and cultural entrepreneurs in the bridging of linguistic, visual, spatial and material turns in the Humanities. We focus on the ways in which buildings (places) are interlaced with layers of meaning and we focus on the processes of inclusion and exclusion performed linguistically, visually, spatially and materially. We are looking at Europe in its post-Second World war, post-colonial and post-Soviet complexities. By now, the consortium consists of 22 academic and non-academic partners from four European countries, plus one university from the USA (notably Harvard University). ${ }^{2}$ INTER(P)LACES has been designed to be submitted to FP7 People, a fraction of FP7 as a whole. ${ }^{3}$ In these two articles, we focus on our 2011-2012 experiences, which include an application for an MC ITN (Marie Curie Initial Training Network) - an application that entails devising a structure of three mobility periods for each prospective student - and an EMJD (Erasmus Mundus Joint Degree) which has two mobilities. We ended the first article with a cliff hanger related to the analysis of the rejection of our EMJD research proposal. We were especially puzzled by the reviewer's report's remark quoted in the last vignette:

24 July 2012... The strong dominance of gender studies experts is not well explained, since gender studies are not a focal point of the proposed research.

\section{The sixty-four-thousand-dollar question}

Applying for research money as gender researchers situated in the corporate university arises from the felt necessity to make sure that Gender Studies and the Social Sciences and Humanities (SSH) stay on the map of the European Commission's research policy. On this map, SSH is a stable 'rest category', and in this rest category the Social Sciences usually win. Most of the monies go to the diversified category of Natural, Biomedical and Technical Sciences. For the ITN 8-9\% went to SSH projects in 2011 and within the EMJD context we are talking about $6 \%$. This allocation of research money thus leads to inequality, or at least to a stabilization of the power distribution within academia. From an overview of successful projects for SSH, we have found out that key words matter: successful applications have 'Europe' in the project title, its subtitle and its overall rationale. But it is also very clear - when we follow the money - that the question of whose Europe is still solidly justified. EC research money appears to flow from centre to periphery in time as 
well as in space. By this, we mean that a comprehensive overview of outcomes of ITN and EMJD applications demonstrates that researchers from countries from the powerful European centre have gradually started to invite Eastern or Southern European scholars to join in on their applications. Our project INTER(P)LACES should have done that too in order to be successful, but the questions of inclusion and exclusion that we want to focus on around a network of museum houses do not ask for paying lip service to the East or the South. This does not mean that power relations within the EU and its neighbouring regions are not on the agenda of our project. In fact, they form the very core of our work. But the empirical obsession of our evaluators did not allow for appreciating the decisions we have made on the symbolic level, i.e. on the level of how stories are being told, whose voices can be heard and whose perspectives remain locked up in the dark corners of history, and/ or which instruments we need in order to develop a sensitivity for the until-now undocumented. So our point is: to include the periphery in the centre is a process which needs thorough thinking about structures of in- and exclusion instead of just taking empirical equality measures. This is exactly what INTER(P)LACES is about. Which stories can be told and which stories remain unimaginable?

We thus would like to signal that, politically speaking, the content of our work neatly mirrors the process that we as Gender Studies scholars comply with when we apply for European research money. The questions of inclusion and exclusion and of the power of definition are at the heart of our work as well as our working environment. But when we do not comply with the accepted idea of gender as a statistical category for research and policy making which only allows for measuring superficial gender equality or commonplaces such as regional spread, but use gender as an analytical category, we don't get the funding. What does it tell us that 'gender', in our complex definition as individual-statistical, social-structural and symbolic variable, does not get through the grant process? The power of definition within the European arena of Higher Education remains constant, and Gender Studies have not been fully integrated. We are not yet part of the power of definition; our definition of in- and exclusion is not integrated.

After the rejections we have mentioned so far, we have continued to apply for the INTER(P)LACES project. Training the next generation of Gender Studies scholars and practising a certain form of intuited trans-generational justice have been and still are our motor. Our feeling is that we have to apply.

\section{Interim conclusions}

How to summarize the findings of our analysis? What does the exercise of looking back at our recent research applications tell us?

\section{Reinforcing existing power relations}

First of all, we have become strongly convinced that the ways in which we are to apply for ITNs and EMJDs reinforce the existing power relations both within Europe itself and in its academia. The model that is built into the document itself as well as what evaluators are to reflect on to measure academic quality reinforces many of the ideals which circle around in our not-so-collective imaginary. The research has to be quantifiable and its effects measurable, i.e. there is a positivist idea about scholarship and management 
speaking through accepted projects and rejection letters. Second, the idea of 'representation' that the EC works with is vehemently flat. 'Europe' itself is an empirically defined entity whose borders are not necessarily invested with meanings and stories, but with numbers. The idea of 'difference' that FP7 works with pertains to numbers too, as it is said that intensive projects that focus on intricate processes of in- and exclusion have to extend to and embrace 'more countries' rather than conduct more complex, multilayered analyses. Third, we can connect to conclusions of other scholars on the effects of all this for the knowledge produced for democracy and freedom. Chandra Mohanty (2003) argued early on, with a reference to Vandana Shiva, that the university has moved from being a public to a private affair, which has severe consequences for the ways in which and for whom knowledges are produced. In addition, a younger feminist scholar, Maria Puíg de la Bellacasa (2001), argued years ago that the university has become a site of immense struggle rather than a space for the free and critical exchange of ideas.

\section{Decentring subjectivity}

What has struck us most in going through and reflecting on several applications for research is that the world that we run around for; email, talk, phone, negotiate and make budgets for; design consortium agreements and joint degree regulations for, does not and will not come to exist in the current situation. We would like to label this as the farreaching decentred subjectivity that comes into being at the corporatized university. Whereas we write and act as if we are chair of the INTER(P)LACES project or supervisor of a certain amount of funded PhD students, we end up empty-handed and disillusioned, just like our consortium partners. Lauren Berlant has famously phrased the new feminist location as follows:

The expansion of the credit economy in Europe and the U.S. once the industrial growth had moved on took care of that, though, purchasing when it couldn't purchase ordinary time, and now that's being revoked too. Plus the revocation of educational democracy, a stand for a public investment in everyone who wanted a shot, is an admission that everyone didn't have a shot, and maybe shouldn't have wanted it. 'How does it feel to be a bad investment?' has substituted itself for 'How does it feel to be a problem?' It makes me speechless, for a minute, to face those blinking phrases, and to consider the whole history that has transpired between them. (Helms et al., 2010: 6)

Laura Fantone (2007) has asked how it is possible to make the precarious lives of young feminists subcontracted by the institution 'liveable'. This question should in fact be posed for all feminists working within the institution and is a site for cooperation of the tenured and non-tenured. And it is to such sites that we want to move next.

\section{Towards possible solutions}

\section{Iris}

9 December 2012. 8 p.m. It is against all odds that I find myself immersed in the discussion of another INTER(P)LACES application on a Sunday evening. Utrecht University 
and Castrum Peregrini have been contacted by a Ukrainian academic centre that wants to work with us around cultural heritage topics. We have shared the latest draft of the $\operatorname{INTER}(P) L A C E S$ application with them in order to check whether they think it complies with the goals of the European Commission's Investing in People programme on 'Supporting Culture as a Vector of Democracy and Economic Growth'. We receive an email: 'Hi Lars and Iris, I agree on all you say about that model of interdependency. It sounds brilliantly thought through. I just think that in our case the academia/university in its scholarly activities also needs to be understood as a place interlaced with layers of meaning. Also, it's hard for me to name any branding agency in Ukraine with the same focus as yours for the entrepreneurial angle. I need to study the question. Will write you more tomorrow. E. 'Indeed, the university is an inter(p)lace too! I email Rosemarie that I think we have to go for it, as this is the kind of remark that will get us going until 17 December, our newest deadline. I decide to leave it for Tuesday though, because I will first have to read a draft chapter by the PhD student that I will meet tomorrow afternoon.

The question that is on the table right now reads: how can academic quality be recognized? We are unwilling to accept the fact that freedom of research leads to a certain form of mainstreaming of critical research, re-establishing the hierarchies we hoped to crumble. The levels we have to take into account are: Europe (empirically and symbolically), academia (what do universities have to be capable of to host projects such as ITN and EMJD?), disciplinarity (the hierarchically ordered tree of academic knowledge production) and difference (how is inclusion into the One, into the drawer of Sameness, as Luce Irigaray would have it, a form of keeping up the gendered hierarchy?). And here are the strategies that we suggest for feminists in the here and now. We see them as continuous with the double-track strategy that feminists have worked with since feminism's early steps on academic territory. First, we want to argue for installing research applications along the lines of a two-stage rocket. Some funding schemas work like this already ${ }^{4}$ and in terms of the intellectual, emotional and physical well-being of applicants, we suggest that all EC and national funding agencies decide to work with a pre-application of five pages and feedback. This way, a certain generosity and co-responsibility is built into the application process; it is simply good manners. Second, we advise the members of the gender studies community - including ourselves - to become evaluators and register on the relevant websites of the $\mathrm{EC}^{5}$ and national governments. This is one attempt at 'integration' and can be a source for an article following up on this one: what happens behind the EC scenes and how to intervene in the current era? Third, and as the counterbalancing gesture of autonomy, we advise the same scholars to connect with feminist $\mathrm{PhD}$ students that already research differently along the lines of an affirmative trans-generational politics (Gronold et al., 2009). After all, our desperate attempts at getting a $\mathrm{PhD}$ programme sorted out did not stop the inflow to our programme of self-financed $\mathrm{PhD}$ students from all over the world! The development and production of gender-sensitive knowledges cannot be halted; these students have already found ways of living liveable lives in the current day academic climate. Fourth, and in the same light, we advise to continue our feminist networking activities from the bottom-up. Only by investing in feminist initiatives such as ATGENDER: The European Association for Gender Research, Education and 
Documentation, ${ }^{6}$ this very European Journal of Women's Studies and other professional activities, can feminist ways of recognizing academic quality be sustained.

\section{Acknowledgements}

A draft of this article has been presented at G12, Nationell Konferens för Genusforskning, Göteborg (panel organized by GenderACT, sponsored by Riksbanken Jubileumsfond) and at the ATGENDER Conference 2013 in Gothenburg. With a thank you to Rasa Navickaite for research assistance.

\section{Notes}

1. www.castrumperegrini.org.

2. The other universities involved are Humboldt-Universität zu Berlin, Alpen Adria Universität Klagenfurt and the University of Sussex.

3. cordis.europa.eu/fp7/people/home_en.html.

4. See e.g. www.cost.eu.

5. ec.europa.eu/research/participants/portal/page/experts

6. www.atgender.eu.

\section{References}

Ahmed S (2007) 'You end up doing the document rather than doing the doing': Diversity, race equality and the politics of documentation. Ethnic and Racial Studies 30(4): 590-609.

Buikema R and Van der Tuin I (2013) Doing the document: Gender studies at the corporatized university in Europe. European Journal of Women's Studies 20(3): 309-316.

Fantone L (2007) Precarious changes: Gender and generational politics in contemporary Italy. Feminist Review 87: 5-20.

Gronold D, Hipfl B and Lund L (eds) (2009) Teaching with the Third Wave: New Feminists' Explorations of Teaching and Institutional Contexts. Stockholm: Stockholm University Press.

Helms G, Vishmidt M and Berlant L (2010) Affect and the politics of austerity: An interview exchange with Lauren Berlant. Variant 39/40: 3-6.

Keeling R (2006) The Bologna Process and the Lisbon Research Agenda: The European Commission's expanding role in higher education discourse. European Journal of Education 41(2): 203-223.

Mohanty CT (2003) 'Under Western Eyes' revisited: Feminist solidarity through anticapitalist struggles. Signs: Journal of Women in Culture and Society 28(2): 499-535.

Puíg de la Bellacasa M (2001) Flexible girls: A position paper on academic genderational politics. In: The Making of European Women's Studies: A Work in Progress Report on Curriculum Development and Related Issues in Gender and Education Research, Vol. 3. Utrecht: ATHENA/Universiteit Utrecht, pp. 95-111. 